\title{
Isomeric Distinction of Small Oligosaccharides: A Bottom-Up Approach Using the Kinetic Method
}

\author{
Mohamed Major, ${ }^{1}$ Thierry Fouquet, ${ }^{1,2}$ Laurence Charles ${ }^{1}$ \\ ${ }^{1}$ Universités Aix-Marseille I, II \& III-CNRS, UMR 6264: Laboratoire Chimie Provence, Spectrométries Appliquées à la \\ Chimie Structurale, Campus Saint-Jérôme, Case 511, 13397 Marseille Cedex 20, France \\ ${ }^{2}$ Department of Advanced Materials and Structures, Centre de Recherche Public Henri Tudor (CRPHT), Esch sur Alzette, \\ Luxembourg
}

\begin{abstract}
Isomeric distinction of di- and tri-saccharides could be efficiently achieved by using data previously obtained while performing experiments aimed at discriminating monosaccharides using trimeric ion dissociation with data analysis by the kinetic method. This study shows that effects observed for lower homologues when one of the partners is changed in the metal/reference system (typically a transition metal divalent cation associated to amino acids) can be extrapolated to upper homologues, at least for the tested analyte series. Systems allowing galactose, glucose, and fructose distinction were used as starting conditions to resolve cellobiose, lactose, maltose, and saccharose disaccharides. When a unique dissociation reaction was observed from the trimeric clusters, a new reference was selected based on its propensity to favor the analyte or the reference release, as revealed from monosaccharide experiments, depending on the desired effect. The same approach could be implemented from data obtained for disaccharides to select efficient metal/ reference systems to distinguish cellotriose, isomaltotriose, maltotriose, and panose trisaccharides. As a result, method optimization is greatly improved due to an enhanced rationalization of the search for discriminant systems. While 40 systems had to be tested for monosaccharides, by screening five transition metals and eight amino acids, the proposed approach allowed efficient metal/reference systems to be found for disaccharides after testing 18 combinations; then, only four systems had to be scrutinized to achieve trisaccharide distinction. Accurate quantitative analyses could be performed in binary mixtures using three-point calibration curves to correct for competition effects between analytes for the formation of the trimeric clusters.
\end{abstract}

Key words: Isomeric distinction, Kinetic method, Disaccharides, Trisaccharides

\section{Introduction}

$\mathrm{O}$ riginally developed for the determination of thermochemical properties of molecules in the gas phase [1],

Electronic supplementary material The online version of this article (doi:10.1007/s13361-011-0128-6) contains supplementary material, which is available to authorized users.

Correspondence to: Laurence Charles; e-mail: laurence.charles@univprovence.fr the kinetic method was further successfully utilized to differentiate and quantify enantiomers in mixture, such as amino acids [2-5], sugars [6], chiral drugs [7-11], and hormones [12]. For the same classes of compounds, the kinetic method has also proven relevant for the distinction of isomers, as reported for peptides [13-16] and amino acids [17], monosaccharides [18] and thyroid hormones [19]. The fundamental concept of isomeric distinction is based on the fact that the nature of the $A_{i}$ isomer involved in the trimeric cluster $\left[\mathrm{M}^{\mathrm{II}}(\operatorname{Ref})_{2}\left(\mathrm{~A}_{\mathrm{i}}\right)-\mathrm{H}\right]^{+}$, generated upon electrospray 
ionization (ESI) of a solution of $A_{i}$ containing a divalent cation $\left(\mathrm{M}^{\mathrm{II}}\right)$ and a reference compound (Ref), affects the kinetics of two competitive unimolecular reactions yielding $\left[\mathrm{M}^{\mathrm{II}}(\mathrm{Ref})\left(\mathrm{A}_{\mathrm{i}}\right)-\mathrm{H}\right]^{+}$after elimination of a neutral reference on one hand, and $\left[\mathrm{M}^{\mathrm{II}}(\mathrm{Ref})_{2}-\mathrm{H}\right]^{+}$by loss of the analyte as a neutral on another hand. From the abundance of these product ions in tandem mass spectrometry (MS/MS), a relative branching ratio $R_{\mathrm{i}}$ for the two competitive dissociation channels is defined for each $A_{i}$ isomer as Equation (1):

$$
R_{\mathrm{i}}=\left[\mathrm{M}^{\mathrm{II}}(\operatorname{Ref})\left(\mathrm{A}_{\mathrm{i}}\right)-\mathrm{H}\right]^{+} /\left[\mathrm{M}^{\mathrm{II}}(\operatorname{Ref})_{2}-\mathrm{H}\right]^{+}
$$

The degree of isomeric distinction of a reference/metal system is measured by $R_{\mathrm{iso}}$, the ratio of $R_{\mathrm{i}}$ to $R_{\mathrm{j}}$ calculated for two $\mathrm{A}_{\mathrm{i}}$ and $\mathrm{A}_{\mathrm{j}}$ isomers, respectively, and increases as the $R_{\text {iso }}$ value differs from unity. Finally, quantitation of $\mathrm{A}_{\mathrm{i}}$ and $\mathrm{A}_{\mathrm{j}}$ isomers in binary mixtures is based on the linear relationship between the relative branching ratio $(R)$ and the molar fraction of one $A_{i}$ isomer $\left(\alpha_{i}\right)$ derived from the kinetic method expression [20, 21]:

$$
\ln R=\alpha_{i} \cdot \ln R_{\mathrm{i}}+\left(1-\alpha_{i}\right) \cdot \ln R_{j}
$$

The efficiency of a system to distinguish two isomers cannot be predicted and is thus empirically established. Based on experimental results from numerous previously reported studies, some guidelines can however be defined. To allow the analyte and the reference to be bound together in a polydentate complex with multiple point interactions [3], transition metal cations are usually employed to generate trimeric clusters. Choosing a reference with a metal affinity close to that of the analyte was shown to allow trimeric clusters to form easily, and thus accurate relative abundance ratios to be measured, but such data are not always available. The similarity of the reference and the analyte in terms of size and functionalities is often a guarantee that entropy effects on fragmentation are negligible, best satisfying this underlying assumption of the kinetic method [3]. Indeed, reported studies dealing with isomeric distinction of di- [13, 16] or tri- [14] peptides were successfully conducted with references containing the same number of amino acids compared with the analytes. However, structural similarity between the analyte and the reference compounds does not always improve the selectivity value, as demonstrated for some $\beta$-amino acid diastereoisomers better distinguished when using $\alpha$-amino acids as the reference [17]. The presence of the same functional groups in both partners is sometimes sufficient. Indeed, best references for isomeric discrimination of monosaccharides using the kinetic method were found to be those amino acids possessing a hydroxyl group, compared with an additional acidic function or an additional amine group [18]. Similarly, using systems involving dipeptides and a transition metal were found to allow $\mathrm{T}_{3}$ and $\mathrm{rT}_{3}$ thyroid hormones to be differentiated [19].
To further rationalize the search for discriminant metal/ reference systems, we explored here the relevance of using data obtained in our previous study dealing with isomeric distinction of monosaccharides (Figure 1) [18] as guidelines in the development of methods targeting upper homologues such as di- and tri-saccharides.

Five cases were encountered while testing forty metal/ reference systems towards three monosaccharide isomers, from which reasonable conclusions could be drawn regarding extrapolation to di- and tri-saccharides:

1. The metal/reference system (further referred to as $\mathrm{M}^{2+}$ / $\operatorname{Ref} / \operatorname{Ref}$ ) was found to induce the required competitive dissociation of the trimeric cluster. Amongst these systems, $\mathrm{Cu}^{2+} / \mathrm{Ser} / \mathrm{Ser}$ and $\mathrm{Mn}^{2+} / \mathrm{Asp} / \mathrm{Asp}$ were the most efficient for monosaccharide quantitation and appear as relevant systems to start method optimization for upper homologues.

2. The metal/reference system failed at generating the trimer of interest, as observed in Figure 1 for all systems involving glutamic acid or arginine as the reference, as well as for $\mathrm{Co}^{2+} / \mathrm{Asp} / \mathrm{Asp}$. The lack of interaction between monosaccharide and the other species within the ionic cluster may suggest these systems would not be adequate for upper saccharide homologues.

3. Extensive secondary dissociations of the targeted product ions were observed, as when $\mathrm{Mn}^{2+}, \mathrm{Fe}^{2+}$, or $\mathrm{Co}^{2+}$ were associated with phenylalanine or serine, or using combinations such as $\mathrm{Cu}^{2+} / \mathrm{Asp} / \mathrm{Asp}$ or $\mathrm{Zn}^{2+} / \mathrm{Ser} / \mathrm{Ser}$ (Figure 1). Occurrence of this deleterious effect in the case of di- or tri-saccharide might be expected but cannot be predicted. As a result, these systems might be tested in a secondary attempt.

4. The trimeric cluster only eliminated the analyte as a neutral, indicating the reference was tightly bound to the metal. In

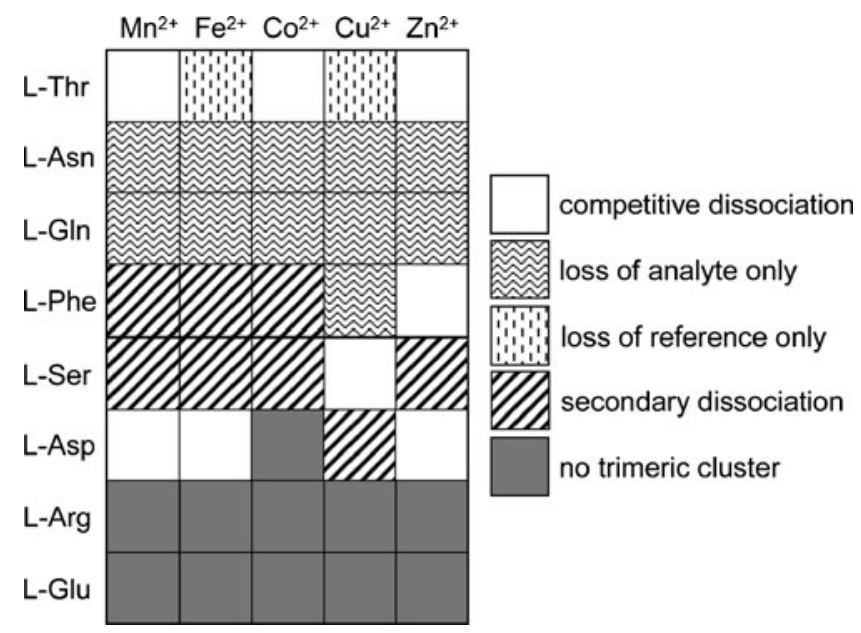

Figure 1. Summary of results obtained while testing combinations of five metal cations and eight amino acid references for isomeric distinction of three monosaccharides ( $D$-fructose, D-galactose, and D-glucose) 
the case of monosaccharides, this behavior was observed for all systems involving asparagine or glutamine, or with $\mathrm{Cu}^{2+}$ / Phe/Phe (Figure 1). Therefore, using a given $\mathrm{M}^{\mathrm{II}}$ transition metal, such references should be chosen whenever the $\mathrm{M}^{\mathrm{II}} /$ reference binding strength is to be enhanced in order to promote the analyte release in CID.

5. The trimeric cluster only eliminated the reference as a neutral, indicating a too high binding strength between the metal and the analyte (as seen for threonine associated to $\mathrm{Fe}^{2+}$ or $\mathrm{Cu}^{2+}$ in Figure 1). Such a reference would thus have to be selected to increase the $\mathrm{M}^{\mathrm{II}} /$ analyte interaction in order to induce the loss of the reference from the trimeric cluster.

As an alternative to an empirical search consisting of testing all 40 systems, the trends observed in the case of monosaccharides will be used here to optimize methods aimed at distinguishing small oligosaccharide isomers using the kinetic method.

\section{Experimental}

\section{Chemicals}

All chemicals used in this study were purchased from Sigma-Aldrich (Saint Louis, MO, USA) and used without further purification. Disaccharide isomers studied as the analytes were cellobiose (cello), lactose (lact), maltose (malt), and saccharose (sacch). Trisaccharide isomers were cellotriose (cellotri), isomaltotriose (isomalt), maltotriose (maltotri), and panose (pano). L-amino acids tested as references were asparagine (Asn), aspartic acid (Asp), glutamine (Gln), phenylalanine (Phe), and serine (Ser). Salts utilized to introduce a divalent cation in solution were $\mathrm{MnCl}_{2}, \mathrm{FeSO}_{4}, \mathrm{Co}\left(\mathrm{CH}_{3} \mathrm{COO}\right)_{2}, \mathrm{ZnCl}_{2}$, and $\mathrm{CuSO}_{4}$. Water was purchased from SDS (Peypin, France) and methanol was from Sigma-Aldrich, these two solvents being of HPLCgrade quality. Electrosprayed samples were aqueous methanol solutions consisting of a mixture of sugar $\left(2.10^{-4} \mathrm{~mol}\right.$ $\left.\mathrm{L}^{-1}\right)$, a reference compound $\left(2.10^{-4} \mathrm{~mol} \mathrm{~L}^{-1}\right)$ and a transition metal $\left(1.10^{-4} \mathrm{~mol} \mathrm{~L}^{-1}\right)$.

\section{Mass Spectrometry}

MS and MS/MS experiments were performed with a 3200 Q-TRAP mass spectrometer (Applied Biosystems SCIEX, Concord, ON, Canada) equipped with an electrospray ionization source operated in positive mode. The capillary voltage was set at $+5500 \mathrm{~V}$ and the cone voltage at $+20 \mathrm{~V}$. This hybrid instrument was used in the triple quadrupole configuration for collision-induced dissociation (CID) experiments. Air was used as the nebulizing gas (10 psi) whereas nitrogen was used as the curtain gas (10 psi) as well as the collision gas. Collision energy was set at the minimal value of $5 \mathrm{eV}$ (laboratory frame). Instrument control, data acquisition and data processing of all experiments were achieved using Analyst software (ver. 1.4.1) provided by Applied Biosystems. Sample solutions were introduced in the ionization source at a $5 \mu \mathrm{L} \mathrm{min}{ }^{-1}$ flow rate using a syringe pump.

\section{Results and Discussion}

\section{Isomeric Resolution of Disaccharides}

Studied disaccharides were selected based on their structural similarities with monosaccharides targeted in our previous study, namely fructose (D-fructopyranose), galactose (D-galactopyranose) and glucose (D-glucopyranose). Accordingly, the four following disaccharides were studied: D-cellobiose ( $\beta$-D-glucopyranosyl-( $1 \rightarrow 4)$-D-glucopyranose), D-lactose ( $\beta$-D-galactopyranosyl-( $(\rightarrow 4)$-D-glucopyranose), D-maltose ( $\alpha$-D-glucopyranosyl-( $1 \rightarrow 4)$-D-glucopyranose), and D-saccharose $(\alpha$-D-glucopyranosyl- $(1 \rightarrow 2)-\beta$-D-fructofuranose) (Scheme 1).

The two most efficient systems for monosaccharide quantitation, i.e., $\mathrm{Cu}^{2+} / \mathrm{Ser} / \mathrm{Ser}$ and $\mathrm{Mn}^{2+} / \mathrm{Asp} / \mathrm{Asp}$, were first tested. Using copper as the central metal and L-serine as the reference, trimeric clusters could be formed with each of the four disaccharides. While the required competitive dissociation was observed upon collisional activation of the trimeric cluster involving cellobiose or saccharose, cluster involving lactose or maltose were observed to mainly dissociate via the loss of serine, suggesting these latter
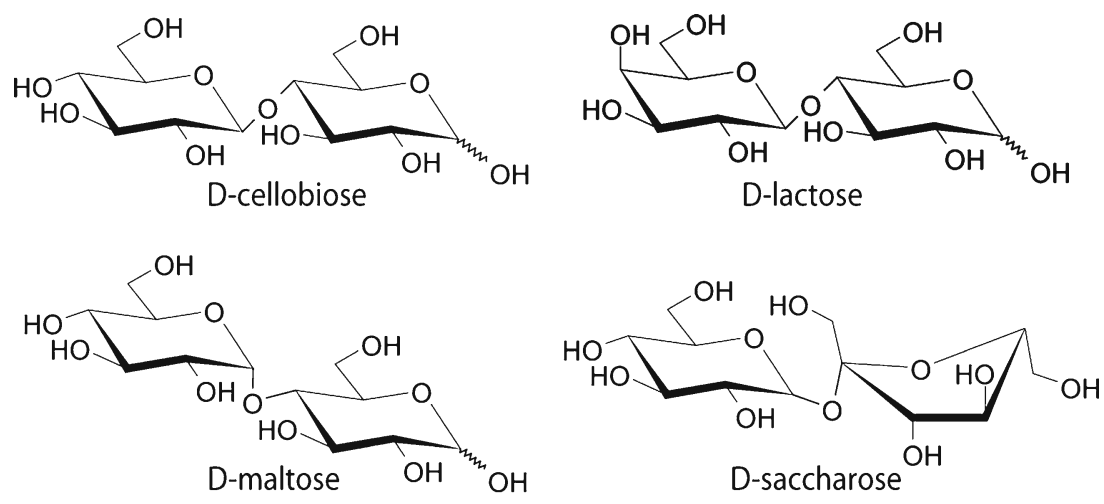

Scheme 1. Chemical structure of the studied disaccharide isomers 
Table 1. Relative Branching Ratio $R_{\mathrm{i}}$ Calculated for the Pure Isomeric Form of D-cellobiose (cello), D-lactose (lact), D-maltose (malt), and Dsaccharose (sacch) Analytes $\left(\mathrm{A}_{\mathrm{i}}\right)$ Using Different Metal Cations $\left(\mathrm{M}^{\mathrm{II}}\right)$ and Asparagine (L-Asn) or Glutamine (L-Gln) as the Reference (Ref)

\begin{tabular}{cllllr} 
& & & & & \\
\cline { 3 - 6 } Ref & $\mathrm{M}^{\mathrm{II}}$ & cello & lact & malt & sacch \\
\hline L-Asn & $\mathrm{Mn}^{2+}$ & 9.73 & 43.8 & 2.51 & 16.25 \\
& $\mathrm{Fe}^{2+}$ & 0.94 & 10.99 & 1.39 & 5.84 \\
& $\mathrm{Co}^{2+}$ & 0.38 & 11.24 & 1.14 & 3.54 \\
\multirow{4}{*}{ L-Gln } & $\mathrm{Zn}^{2+}$ & 1.08 & 11.12 & 1.39 & 5.71 \\
& $\mathrm{Mn}^{2+}$ & 1.87 & 9.13 & 1.08 & 1.99 \\
& $\mathrm{Fe}^{2+}$ & 0.41 & 7.09 & 0.72 & 2.69 \\
& $\mathrm{Co}^{2+}$ & 0.16 & 5.32 & 0.56 & 1.45 \\
& $\mathrm{Zn}^{2+}$ & 0.04 & 0.66 & 0.10 & 0.12 \\
\hline
\end{tabular}

analytes were more strongly bound to the metal compared with the reference. Maltose differs from cellobiose only by the configuration of the anomeric carbon (Scheme 1) and the change in CID behavior when cellobiose is changed to maltose suggests that one sugar ring interacts with the metal center and/or the reference for one disaccharide analyte while two sugar rings are involved in the binding for the other one. Results obtained for lactose can also be accounted for when considering monosaccharide data. Compared with cellobiose, lactose contains galactose instead of glucose as the second residue (Scheme 1), and while analyzed as a monosaccharide, galactose was shown to be more strongly bound within the $\left[\mathrm{Cu}^{\mathrm{II}}(\mathrm{Ser})_{2}\left(\mathrm{~A}_{\mathrm{i}}\right)-\mathrm{H}\right]^{+}$trimeric cluster $\left(R_{\mathrm{i}}=0.420\right)$ compared with glucose $\left(R_{\mathrm{i}}=0.161\right)$ [18].

Keeping the same metal, the trimeric cluster composition was thus modified to include one reference molecule expected to favor the release of disaccharide. Since data from Figure 1 indicate that systems involving $\mathrm{Cu}^{2+}$ and phenylalanine (Phe), asparagine (Asn), or glutamine (Gln) dissociate via the loss of the monosaccharide analyte only, these three amino acids were tested together with serine. Although these new systems allowed competitive dissociation in the case of three disaccharides, trimeric clusters involving lactose still failed at releasing the analyte. To address the case of lactose, the next step in the search for adequate metal/reference systems consisted of changing both serine references in the $\mathrm{Cu}^{2+} / \mathrm{Ser} / \mathrm{Ser}$ system in order to further favor the reaction giving rise to the analyte release. Different results were obtained depending on the tested reference. While $\mathrm{Cu}^{2+} / \mathrm{Phe} / \mathrm{Phe}$ still failed in the case of lactose, $\mathrm{Cu}^{2+} / \mathrm{Asn} / \mathrm{Asn}$ and $\mathrm{Cu}^{2+} / \mathrm{Gln} / \mathrm{Gln}$ both allowed this analyte to be efficiently released from trimeric precursor ions, giving rise to $R_{\mathrm{i}}$ values of low magnitude $(0.2$ and 0.5 , respectively). These results show that as expected, the binding strength between the metal and the reference has increased. However, this binding strength was too high for the cases of the three other tested disaccharides since these analytes were released as neutrals from the $\left[\mathrm{Cu}^{\mathrm{II}}(\mathrm{Asn})_{2}\left(\mathrm{~A}_{\mathrm{i}}\right)-\mathrm{H}\right]^{+}$or $\left[\mathrm{Cu}^{\mathrm{II}}\right.$ $\left.(\mathrm{Gln})_{2}\left(\mathrm{~A}_{\mathrm{i}}\right)-\mathrm{H}\right]^{+}$trimeric complex.

Since none of the systems involving $\mathrm{Cu}^{2+}$ as the central metal was found to distinguish all the targeted disaccharides, the same optimization approach was applied starting from $\mathrm{Mn}^{2+} / \mathrm{Asp} / \mathrm{Asp}$, the second system found to be efficient for quantitative discrimination of monosaccharides. Trimeric clusters could be generated for all disaccharides from mixtures containing $\mathrm{Mn}^{2+}$, aspartic acid, and one analyte, but the required competitive dissociation for the kinetic method to be used was only observed in the case of maltose. Since aspartic acid was systematically released as a neutral from $\left[\mathrm{Mn}^{\mathrm{II}}(\mathrm{Asp})_{2}\left(\mathrm{~A}_{\mathrm{i}}\right)-\mathrm{H}\right]^{+}$in the three other cases, trimeric clusters involving a more strongly bound reference were targeted to allow the release of the analyte to compete more efficiently with the elimination of the reference. Based on data obtained using manganese as the metal (Figure 1), asparagine and glutamine were identified as best candidates. These two amino acids were first used together with aspartic acid by implementing the fixed ligand version of the kinetic method [9]. With the $\mathrm{Mn}^{2+} / \mathrm{Asp} / \mathrm{Asn}$ system, a lower $R_{\mathrm{i}}$ value (10.3) was found for maltose compared with results obtained for this analyte using the $\mathrm{Mn}^{2+} / \mathrm{Asp} / \mathrm{Asp}$ system $\left(R_{\mathrm{i}}=25.9\right)$, consistently with the decrease of the abundance of the $\left[\mathrm{Mn}^{\mathrm{II}}\right.$ (Asn)(malt) $-\mathrm{H}]^{+}$product ion in the CID spectrum. However, using the $\mathrm{Mn}^{2+} / \mathrm{Asp} / \mathrm{Asn}$ system, the release of aspartic acid as a neutral was the only dissociation reaction experienced by clusters involving any other disaccharide. Changing Asn to Gln did not improve the results: no $R_{\mathrm{i}}$ value could be calculated for any analytes. In contrast, competitive dissociation reactions were observed from all trimeric clusters using $\mathrm{Mn}^{2+} / \mathrm{Asn} / \mathrm{Asn}$ or $\mathrm{Mn}^{2+} / \mathrm{Gln} / \mathrm{Gln}$, and calculated $R_{\mathrm{i}}$ values are presented in Table 1. Nonetheless, the $\mathrm{Mn}^{2+} / \mathrm{Gln} / \mathrm{Gln}$ system could not further be considered due to a lack of distinction between D-cellobiose and D-saccharose $\left(R_{\mathrm{i}}=1.87\right.$ and $R_{\mathrm{i}}=1.99$, respectively). In contrast, the $\mathrm{Mn}^{2+} / \mathrm{Asn} / \mathrm{Asn}$ system yielded very

Table 2. Isomeric Recognition of D-cellobiose (cello), D-lactose (lact), D-maltose (malt), and D-saccharose (sacch) using $\mathrm{Fe}^{2+}$ or $\mathrm{Co}^{2+}$ as the Metal Cation and L-asparagine (Asn) or L-glutamine (Gln) as the Reference

\begin{tabular}{|c|c|c|c|c|c|c|}
\hline & \multicolumn{6}{|c|}{$R_{\text {iso }}(\sigma)^{\mathrm{a}}$} \\
\hline & lact/malt & lact/sacch & lact/cello & malt/sacch & malt/cello & sacch/cello \\
\hline $\mathrm{Fe}^{2+} / \mathrm{Asn} / \mathrm{Asn}$ & $7.9(0.9)$ & $1.7(0.4)$ & $11.6(0.4)$ & $0.22(0.07)$ & $1.5(0.3)$ & $6.3(0.9)$ \\
\hline $\mathrm{Fe}^{2+} / \mathrm{Gln} / \mathrm{Gln}$ & $9.8(0.2)$ & $2.64(0.06)$ & $17.4(0.6)$ & $0.27(0.01)$ & $1.77(0.05)$ & $6.6(0.2)$ \\
\hline $\mathrm{Co}^{2+} / \mathrm{Asn} / \mathrm{Asn}$ & $9.9(0.1)$ & $3.17(0.06)$ & $29.8(0.5)$ & $0.32(0.01)$ & $3.01(0.09)$ & $9.4(0.2)$ \\
\hline $\mathrm{Co}^{2+} / \mathrm{Gln} / \mathrm{Gln}$ & $9.5(0.3)$ & $3.7(0.2)$ & $34.0(0.2)$ & $0.38(0.02)$ & $3.6(0.1)$ & $9.3(0.2)$ \\
\hline
\end{tabular}

${ }^{\mathrm{a}}$ Standard deviation calculated on five replicate experiments. 
Figure 2. ESI-MS/MS product ion spectra of trimeric complex ions at $\mathrm{m} / \mathrm{z} 664.1$ containing (a) D-cellobiose, [Co( $\mathrm{L}-$ Asn $)_{2}(\mathrm{D} \text {-cello) }-\mathrm{H}]^{+}$, (b) D-lactose, $\left[\mathrm{Co}(\mathrm{L}-\mathrm{Asn})_{2}(\mathrm{D} \text {-lact })-\mathrm{H}\right]^{+}$, (c) D-maltose, $\left[\mathrm{Co}(\mathrm{L}-\mathrm{Asn})_{2}(\mathrm{D}-\mathrm{malt})-\mathrm{H}\right]^{+}$, and (d) D-saccharose, $\left[\mathrm{Co}(\mathrm{L}-\mathrm{Asn})_{2}(\mathrm{D}-\mathrm{sacch})-\mathrm{H}\right]^{+}$, using a $5 \mathrm{eV}$ collision energy (laboratory frame)

different branching ratios for all tested disaccharides, ensuring

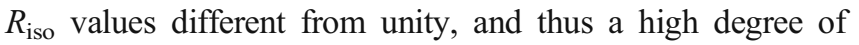
isomer distinction. However, when considering uncertainties associated with $R_{\mathrm{i}}$ values (calculated from five replicate experiments but not reported in Table 1 for sake of clarity), data obtained for lactose when using the $\mathrm{Mn}^{2+} / \mathrm{Asn} / \mathrm{Asn}$ system were poorly repeatable (relative standard deviation of $15 \%$ ) due to the low abundance of the $\left[\mathrm{Mn}^{\mathrm{II}}(\mathrm{Asn})_{2}-\mathrm{H}\right]^{+}$product ion.

To test systems involving alternative transition metals in an efficient manner, the next optimization step focused on the combination of $\mathrm{Fe}^{2+}, \mathrm{Co}^{2+}$, or $\mathrm{Zn}^{2+}$ with asparagine or glutamine, previously evidenced to be tightly bound to the metal and, thus, expected to be relevant in the challenging case of lactose. Results obtained while performing experiments with these six new combinations are in agreement with the predicted trend: the two competitive dissociation reactions occurred from all $\left[\mathrm{M}^{\mathrm{II}}(\mathrm{Ref})_{2} \text { (disaccharide) }-\mathrm{H}\right]^{+}$ precursor ions, in particular those including lactose (Table 1). To ensure a good repeatability of quantitative results, systems involving $\mathrm{Zn}^{2+}$ were no further considered since one of the targeted product ions was measured with very low abundance for at least one of the three analytes, giving rise to high uncertainty levels. For example, the very low $R_{\mathrm{i}}$ value calculated in the case of cellobiose (Table 1) reflects the poor abundance of the $\left[\mathrm{Zn}^{\mathrm{II}}(\mathrm{Gln}) \text { (cellobiose) }-\mathrm{H}\right]^{+}$ product ion, while peaks measured for both product ions upon CID of the $\left[\mathrm{Zn}^{\mathrm{II}}(\mathrm{Asn})_{2}(\text { lactose })-\mathrm{H}\right]^{+}$cluster were of weak intensity. Amongst the four remaining combinations, $\mathrm{Fe}^{2+} / \mathrm{Gln} / \mathrm{Gln}, \mathrm{Co}^{2+} / \mathrm{Gln} / \mathrm{Gln}$, and $\mathrm{Co}^{2+} / \mathrm{Asn} / \mathrm{Asn}$ were selected for further disaccharide quantitative analysis since they were associated with $R_{\text {iso }}$ values the most different from unity and the most different for all analyte pairs (Table 2). Interestingly, the two amino acids involved in the most discriminant systems exhibit a very similar structure, $\mathrm{H}_{2} \mathrm{~N}$ (CO)- $\left(\mathrm{CH}_{2}\right)_{n}-\mathrm{CH}\left(\mathrm{NH}_{2}\right)-\mathrm{COOH}$ with $n=1$ for asparagine and $n=2$ for glutamine.

Disaccharide isomeric distinction is illustrated in Figure 2, with the example of the system composed of asparagine as the reference and cobalt as the central metal. From these CID spectra, it could be noted that in contrast to the case of monosaccharides but similar to most reported studies dealing with chiral recognition using the kinetic method, the base peak in the MS/MS spectra is the precursor ion.

\section{Isomeric Resolution of Trisaccharides}

Systems found to be efficient for isomeric distinction of disaccharides were then tested for a series of four trisaccharides (Scheme 2), all containing three glucose units but (a)

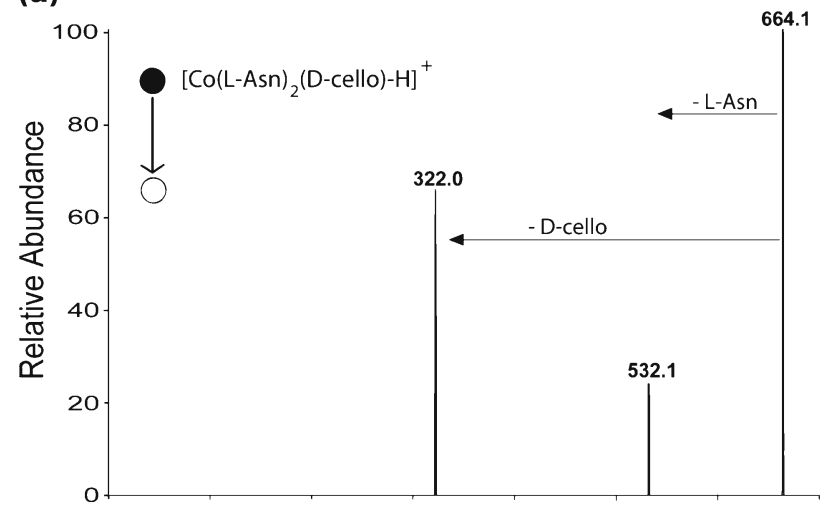

(b)

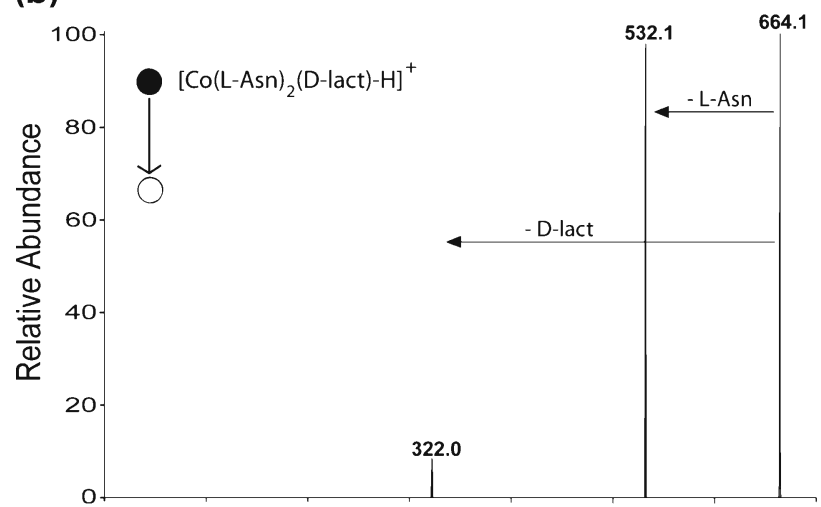

(c)

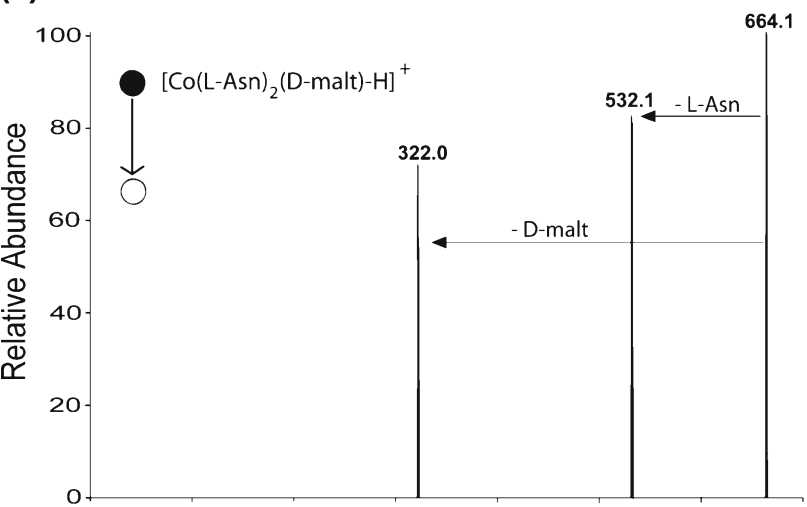

(d)

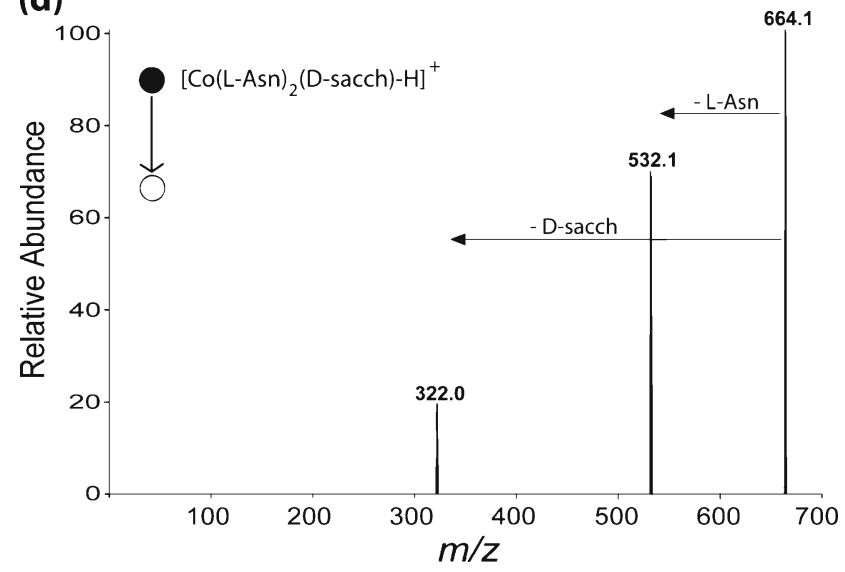


different glycosidic bonds: D-cellotriose ( $\beta$-D-glucopyranosyl-( $1 \rightarrow 4)$ - $\beta$-D-glucopyranosyl-( $1 \rightarrow 4)$-D-glucopyranose), D-maltotriose $(\alpha$-D-glucopyranosyl-( $1 \rightarrow 4)-\alpha$-D-glucopyranosyl-( $1 \rightarrow 4)$-D-glucopyranose), D-isomaltotriose ( $\alpha$-D-glucopyranosyl-( $(1 \rightarrow 6)-\alpha$-D-glucopyranosyl-( $1 \rightarrow 6)$-D-glucopyranose), and D-panose ( $\alpha$-D-glucopyranosyl-(1 $\rightarrow 6)-\alpha-\mathrm{D}$ glucopyranosyl-(1 $\rightarrow 4)$-D-glucopyranose).

Using $\mathrm{Fe}^{2+} / \mathrm{Gln} / \mathrm{Gln}, \mathrm{Co}^{2+} / \mathrm{Gln} / \mathrm{Gln}$ or $\mathrm{Co}^{2+} / \mathrm{Asn} / \mathrm{Asn}$, trimeric clusters were formed for all tested analytes and were shown to dissociate via the two expected competitive dissociations upon activation (Table 3). Extremely high $R_{\mathrm{i}}$ values were systematically obtained for cellotriose, reflecting a weak loss of the analyte regardless of the metal/ reference combination used. In order to lower these $R_{\mathrm{i}}$ values to ensure a better repeatability of the measurements, an alternative metal/reference had to be investigated with the aim of favoring the release of the analyte. Since cellotriose is the trisaccharidic homologue of cellobiose, results obtained for this disaccharide were more closely scrutinized. Considering the best (lowest) $R_{\mathrm{i}}$ value was obtained for cellotriose with $\mathrm{Co}^{2+} / \mathrm{Gln} / \mathrm{Gln}$ (Table 3), the lowest $R_{\mathrm{i}}$ value associated to cellobiose when using the same reference was measured from experiments involving zinc as the metal cation $\left(R_{\mathrm{i}}=\right.$ 0.04 in Table 1), indicating this disaccharide was readily released as a neutral from $\left[\mathrm{Zn}^{\mathrm{II}}(\mathrm{Gln})_{2} \text { (cellobiose) }-\mathrm{H}\right]^{+}$. Consistent with the effect observed for cellobiose, the $\mathrm{Zn}^{2+}$ / Gln/Gln system indeed allowed an enhanced release of cellotriose from the so-formed trimeric cluster, yielding a $R_{\mathrm{i}}$ value of 10.52 . This system was thus tested for the other trisaccharide isomers but, compared with the $\mathrm{Co}^{2+} / \mathrm{Gln} /$ Gln system, it was found to provide a lower degree of distinction towards these isomers (Table 4). As a compromise, it was concluded that glutamine should be used together with zinc for quantitation of cellotriose in mixture containing another disaccharide isomer while associated to cobalt for distinction of isomaltotriose, maltotriose, and panose.

\section{Quantitative Analysis}

The three systems $\left(\mathrm{Fe}^{2+} / \mathrm{Gln} / \mathrm{Gln}, \mathrm{Co}^{2+} / \mathrm{Gln} / \mathrm{Gln}\right.$, and $\mathrm{Co}^{2+} /$ Asn/Asn) selected for disaccharides were used for quantitation in binary mixtures. The linear relationship between $\ln R$ and the content of isomers in a sample Equation (2), as predicted by the kinetic method when assuming the common associated approximations are satisfied, actually implies that the two $A_{i}$ and $A_{j}$ isomers within a binary mixture react equally toward the reference and the transition metal. In our previous study on monosaccharides, it was evidenced that the presence of an $A_{i}$ isomer in the sample strongly modified the production of the trimeric complex ion involving a second $A_{j}$ isomer [18]. Similar competition effects were observed for disaccharides: large deviations from linearity were observed when analyzing binary 50/50 isomeric mixtures based on two-point calibration lines (data not shown). As a result, the three-point calibration $(0,50$ and $100 \%$ ) procedure, successfully applied to monosaccharide isomers, was also implemented here (see details of this procedure in Supplemental Information). The so-established three-point calibration curves were used to quantify disaccharides in different binary samples. Data from Table 5 first show that results of similar quality were obtained using one or the other metal/reference system for isomeric distinction. Very good results were obtained, with relative errors in the range $0.4 \%-3.6 \%$ for the lowest sugar molar fraction and $0.8 \%-3.3 \%$ for the highest relative concentration, when excluding data measured for the lowest amount of D-maltose in the presence of D-cellobiose, which were less accurate (relative error of up to 7.2\%). For monosaccharides, based on the reasonable assumption that the presence of a third $A_{k}$ isomer in the sample would not modify the extend of the effect of $A_{j}$ towards $A_{i}$, as measured in binary mixtures, quantitative analysis could be successfully performed in ternary mixtures [18]. In contrast, such an approach failed at quantifying a disaccharide in the

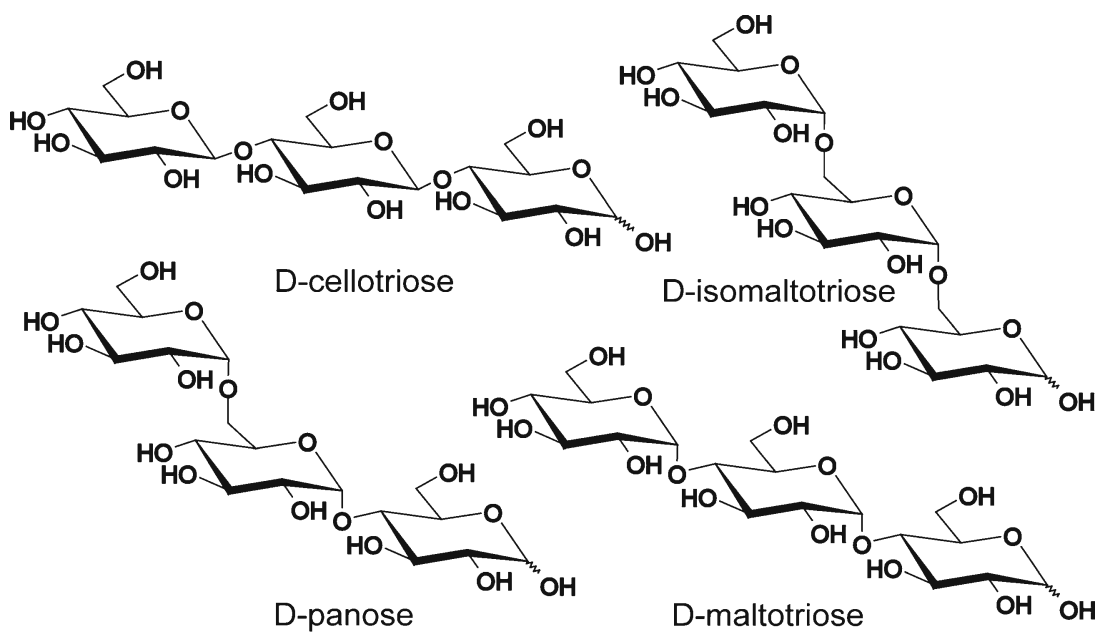

Scheme 2. Chemical structure of the studied trisaccharide isomers 
Table 3. Relative Branching Ratio $R_{\mathrm{i}}$ Calculated for the Pure Isomeric Form of D-maltotriose (maltotri), D-isomaltose (isomalt), D-cellotriose (cellotri), and D-panose (pano) Analytes $\left(\mathrm{A}_{\mathrm{i}}\right)$ Using the $\mathrm{Co}^{2+} / \mathrm{Asn} / \mathrm{Asn}, \mathrm{Co}^{2}$ ${ }^{+} / \mathrm{Gln} / \mathrm{Gln}$, and $\mathrm{Fe}^{2+} / \mathrm{Asn} / \mathrm{Asn}\left(\mathrm{M}^{\mathrm{II}} / \mathrm{Ref} /\right.$ Ref) Systems

\begin{tabular}{lccccc}
\cline { 3 - 5 } $\mathrm{M}^{\mathrm{II}}$ & Ref & maltotri & isomalt & cellotri & pano \\
\hline $\mathrm{Co}^{2+}$ & L-Asn & 12.71 & 26.27 & 257.4 & 38.20 \\
& L-Gln & 4.41 & 9.52 & 110.9 & 11.01 \\
$\mathrm{Fe}^{2+}$ & L-Asn & 6.21 & 22.89 & 131.7 & 15.23
\end{tabular}

presence of two other congeners, suggesting that disaccharide ternary samples could not be considered as the mixture of the three pairs $A_{i} / A_{j}, A_{i} / A_{k}$ and $A_{j} / A_{k}$ in terms of competition effects.

Similarly, quantitative analysis of trisaccharides could only be performed in binary mixtures using three-point calibration curves such as those depicted in Figure 3. For example, using the $\mathrm{Zn}^{2+} / \mathrm{Gln} / \mathrm{Gln}$ system, quantitative data obtained for cellotriose at a molar ratio of $25 \%$ and $75 \%$ in a binary mixture containing panose were, respectively, $28.7 \%$ and $73.0 \%$. Results of similar accuracy were found from other binary mixtures: using the $\mathrm{Co}^{2+} / \mathrm{Gln} / \mathrm{Gln}$ for quantitation of maltotriose (molar ratio: $25 \%$ and $75 \%$ ) in mixture with isomaltotriose, molar fraction of $28.5 \%$ and $73.2 \%$ were obtained, respectively.

\section{Conclusion}

The approach consisting of using results from monosaccharides to optimize metal/reference systems aimed at discriminating disaccharides, and then data from disaccharides to develop a method to resolve trisaccharide isomers, was demonstrated here to be relevant. In particular, MS/MS data obtained for trimeric clusters involving low congener analytes could be usefully employed to predict the impact of changing the reference compound on the dissociation behavior of $\left[\mathrm{M}^{\mathrm{II}}(\operatorname{Ref})_{2}\left(\mathrm{~A}_{\mathrm{i}}\right)-\mathrm{H}\right]^{+}$precursor ions containing higher congeners as the analyte. This approach allowed a substantial time-saving in the search for the adequate metal/ reference systems: compared with the $40 \mathrm{metal} / \mathrm{reference}$ combinations tested for monosaccharide distinction, only 18 ones had to be scrutinized in the case of disaccharide isomers, and experiments using 4 systems were sufficient to

Table 4. Isomeric Recognition of D-maltotriose (maltotri), D-isomaltose (isomalt), and D-panose (pano) using $\mathrm{Co}^{2+}$ or $\mathrm{Zn}^{2+}$ as the Metal Cation and L-Glutamine (Gln) as the Reference (Ref)

\begin{tabular}{llc}
\hline & \multicolumn{2}{c}{$R_{\text {iso }}(\sigma)^{\mathrm{a}}$} \\
\cline { 2 - 3 } & $\mathrm{Co}^{2+} / \mathrm{G} \ln / \mathrm{Gln}$ & $\mathrm{Zn}^{2+} / \mathrm{Gln} / \mathrm{Gln}$ \\
\cline { 2 - 3 } isomalt/maltotri & $2.17(0.02)$ & $1.16(0.04)$ \\
pano/maltotri & $2.50(0.03)$ & $1.52(0.04)$ \\
pano/isomalt & $1.16(0.09)$ & $1.30(0.03)$ \\
\hline
\end{tabular}

${ }^{\text {a }}$ Standard deviation calculated on five replicate experiments.
Table 5. Quantification of Disaccharides in Binary Isomeric Mixtures using a Three-Point Calibration

\begin{tabular}{|c|c|c|c|c|}
\hline & \multicolumn{4}{|c|}{ Isomeric fraction $\%(\sigma)^{\mathrm{a}}$} \\
\hline & actual & $\mathrm{Fe}^{2+} / \mathrm{Gln} / \mathrm{Gln}$ & $\mathrm{Co}^{2+} / \mathrm{Gln} / \mathrm{Gln}$ & $\mathrm{Co}^{2+} / \mathrm{Asn} / \mathrm{Asn}$ \\
\hline \multicolumn{5}{|c|}{ D-maltose $+D$-lactose } \\
\hline \multirow[t]{3}{*}{$\alpha_{\text {D-lact,1 }}$} & 25 & $24.9(0.9)$ & $25.5(0.9)$ & $25.5(0.7)$ \\
\hline & 50 & $50.0^{\mathrm{b}}(1.1)$ & $50.0^{\mathrm{b}}(0.6)$ & $50.0^{\mathrm{b}}(0.7)$ \\
\hline & 75 & $74.4(0.8)$ & $74.3(0.5)$ & $73.5(0.6)$ \\
\hline \multicolumn{5}{|c|}{ D-cellobiose $+D$-maltose } \\
\hline \multirow[t]{3}{*}{$\alpha_{\mathrm{D}-\mathrm{malt}, 1}$} & 25 & $26.8(4.3)$ & $24.7(1.1)$ & $26.8(1.5)$ \\
\hline & 50 & $50.0^{\mathrm{b}}(2.4)$ & 49.7 (1.6) & $50.0^{\mathrm{b}}(2.1)$ \\
\hline & 75 & $77.1(1.8)$ & $76.1(5.0)$ & 72.5 (1.9) \\
\hline \multicolumn{5}{|c|}{ D-cellobiose $+D$-saccharose } \\
\hline \multirow{3}{*}{$\alpha_{\mathrm{D}-\mathrm{sacch}, 1}$} & 25 & $24.5(0.7)$ & $25.1(0.5)$ & $25.9(0.8)$ \\
\hline & 50 & $50.0^{\mathrm{b}}(0.8)$ & $50.0^{\mathrm{b}}(1.7)$ & $50.0^{\mathrm{b}}(0.8)$ \\
\hline & 75 & $76.4(1.2)$ & $74.2(0.8)$ & $73.8(0.6)$ \\
\hline
\end{tabular}

${ }^{a}$ Standard deviation calculated on five replicate experiments.

${ }^{\mathrm{b}}$ Used as standard.

address the case of trisaccharides. Quantitation capabilities using the so-optimized systems have also been evaluated: although restricted to binary mixture analysis, somehow limiting the scope of their applications, the developed methods provide accurate and precise results for both diand tri-saccharides in a simple, precise, and robust manner. As previously evidenced for monosaccharides, the use of three-point calibration curves was necessary to take into account competition effects between two isomers for the formation of trimeric complexes.

From a mechanistic point of view, it is interesting to note that although amino acids used as the reference greatly differ from the analytes in terms of size (compared with the case of monosaccharides), they were found to allow trimeric clusters with isomer-specific interactions to be formed. Moreover,

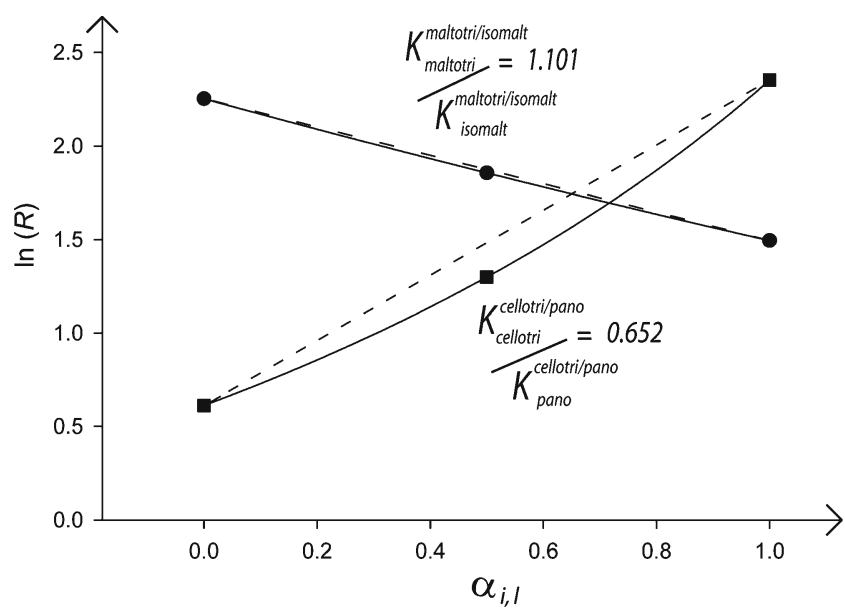

Figure 3. Three-point corrected calibration curves used for quantitative analysis of (filled circle) D-maltotriose (maltotri) in the presence of D-isomaltotriose (isomalt) using the $\mathrm{Zn}^{2+}$ / Gln/Gln system, and (filled square) D-cellotriose (cellotri) in the presence of D-panose (pano) using the $\mathrm{Co}^{2+} / \mathrm{Gln} / \mathrm{Gln}$ system 
the great differences in dissociation behavior induced by slight structural differences on one or the other residue in disaccharides, as observed when comparing cellobiose with maltose or lactose using the $\mathrm{Cu}^{2+} / \mathrm{Ser} / \mathrm{Ser}$ system, suggest that for some isomers, both sugar units would play a role in the structuring of the trimeric cluster while for others, only one sugar ring would interact with the metal and/or reference partners. In addition, opposite conclusions drawn from experiments performed for cellobiose and maltose, while changing the discriminant system from $\mathrm{Cu}^{2+} / \mathrm{Ser} / \mathrm{Ser}$ to $\mathrm{Mn}^{2+}$, Asp/Asp further confirms, as reported in most studies dealing with the kinetic method, that the way the analyte is involved in the trimeric cluster is dictated by the nature of the $\mathrm{M}^{\mathrm{II}} /$ reference couple.

\section{Acknowledgments}

L.C. acknowledges support from Spectropole, the Analytical Facility of Aix-Marseille University, by allowing a special access to the instruments purchased with European Funding (FEDER OBJ2142-3341).

\section{References}

1. Tao, W.A., Cooks, R.G.: Chiral Analysis by MS. Anal. Chem. 75, 25A$31 \mathrm{~A}(2003)$

2. Tao, W.A., Zhang, D.X., Wang, F., Thomas, P.D., Cooks, R.G.: Kinetic Resolution of D, L-Amino Acids Based on Gas-Phase Dissociation of Copper(II) Complexes. Anal. Chem. 71, 4427-4429 (1999)

3. Tao, W.A., Zhang, D.X., Nikolaev, E.N., Cooks, R.G.: Copper(II)Assisted Enantiomeric Analysis of D, L-Amino Acids Using the Kinetic Method: Chiral Recognition and Quantification in the Gas Phase. J. Am. Chem. Soc. 122, 10598-10609 (2000)

4. Zhang, D.X., Tao, W.A., Cooks, R.G.: Chiral resolution of D-, LAmino Acids by Tandem Mass Spectrometry of Ni(II)-Bound Trimeric Complexes. Int. J. Mass Spectrom. 204, 159-169 (2001)

5. Wu, L.M., Tao, W.A., Cooks, R.G.: Kinetic Method for the Simultaneous Chiral Analysis of Different Amino Acids in Mixtures. J. Mass Spectrom. 38, 386-393 (2003)

6. Augusti, D.V., Carazza, F., Augusti, R., Tao, W.A., Cooks, R.G.: Quantitative Chiral Analysis of Sugars by Electrospray Ionization Tandem Mass Spectrometry Using Modified Amino Acids as Chiral Reference Compounds. Anal. Chem. 74, 3458-3462 (2002)

7. Tao, W.A., Gozzo, F.C., Cooks, R.G.: Mass Spectrometric Quantitation of Chiral Drugs by the Kinetic Method. Anal. Chem. 73, 1692-1698 (2001)
8. Tao, W.A., Wu, L.M., Cooks, R.G., Wang, F., Begley, J.A., Lampert, B.: Rapid Enantiomeric Quantification of an Antiviral Nucleoside Agent (D, L-FMAU, 2'-Fluoro-5-Methyl- $\beta$, D, L-Arabinofurano-Syluracil) by Mass Spectrometry. J. Med. Chem. 44, 3541-3544 (2001)

9. Wu, L.M., Meurer, E.C., Cooks, R.G.: Chiral Morphing and Enantiomeric Quantification in Mixtures by Mass Spectrometry. Anal. Chem. 76, 663-671 (2004)

10. Lee, M.K., Kumar, A.P., Jin, D., Lee, Y.I.: Determination of Enantiomeric Compositions of DOPA by Tandem Mass Spectrometry Using the Kinetic Method with Fixed Ligands. Rapid Commun. Mass Spectrom. 22, 909-915 (2008)

11. Ramagiri, S., Gupte, R., Rakov, I., Yates, C.R., Miller, D.D.: Quantitative Chiral Analysis of Phthaloylglutamic Acid and Related Analogs by a Single Ratio Kinetic Method Using Electrospray Ionization and Matrix-Assisted Laser Desorption Techniques. Rapid Commun. Mass Spectrom. 22, 639-646 (2008)

12. Lee, M.K., Kumar, A.P., Lee, Y.I.: Kinetic Method for Enantiomeric Determination of Thyroid Hormone (D, L-Thyroxine) Using Electrospray Ionization Tandem Mass Spectrometry (ESI-MS/MS). Int. J. Mass Spectrom. 272, 180-186 (2008)

13. Tao, W.A., Wu, L.M., Cooks, R.G.: Differentiation and Quantitation of Isomeric Dipeptides by Low-Energy Dissociation of Copper(II)-Bound Complexes. J. Am. Soc. Mass Spectrom. 12, 490-496 (2001)

14. Wu, L.M., Lemr, K., Aggerholm, T., Cooks, R.G.: Recognition and Quantification of Binary and Ternary Mixtures of Isomeric Peptides by the Kinetic Method: Metal Ion and Ligand Effects on the Dissociation of Metal-Bound Complexes. J. Am. Soc. Mass Spectrom. 14, 152-160 (2003)

15. Wu, L.M., Meurer, E.C., Young, B., Yang, P.X., Eberlin, M.N., Cooks, R.G.: Isomeric Differentiation and Quantification of $\alpha \beta$-Amino AcidContaining Tripeptides by the Kinetic Method: Alkali Metal-Bound Dimeric Cluster Ions. Int. J. Mass Spectrom. 231, 103-111 (2004)

16. Schug, K.A., Lindner, W., Lemr, K.: Isomeric Discrimination of Arginine-Containing Dipeptides Using Electrospray Ionization-Ion Trap Mass Spectrometry and the Kinetic Method. J. Am. Soc. Mass Spectrom. 15, 840-847 (2004)

17. Hyyrylainen, A.R.M., Pakarinen, J.M.H., Fulop, F., Vainiotalo, P.: Diastereochemical Differentiation of Some Cyclic and Bicyclic $\beta$ Amino Acids, Via the Kinetic Method. J Am. Soc. Mass Spectrom. 20, 34-41 (2009)

18. Fouquet, T., Charles, L.: Distinction and Quantitation of Sugar Isomers in Ternary Mixtures Using the Kinetic Method. J. Am. Soc. Mass Spectrom. 21, 60-67 (2010)

19. Kumar, A.P., Jin, H., Jo, S.C., Kim, C., Nam, S.H., Lee, Y.I.: Isomeric Discrimination and Quantification of Thyroid Hormones, T-3 and rT(3), by the Single Ratio Kinetic Method Using Electrospray Ionization Mass Spectrometry. J. Am. Soc. Mass Spectrom. 21, 14-22 (2010)

20. Cooks, R.G., Patrick, J.S., Kotiaho, T., McLuckey, S.A.: Thermochemical Determinations by the Kinetic Method. Mass Spectrom. Rev. 13, 287-339 (1994)

21. Cooks, R.G., Wong, P.S.H.: Kinetic Method of Making Thermochemical Determinations: Advances and Applications. Acc. Chem. Res. 31, 379-386 (1998) 